\title{
Trends in Recall and Appraisal of Anti-Smoking Advertising Among American Youth: National Survey Results, 1997-2001
}

\author{
Lloyd D. Johnston, ${ }^{1,3}$ Yvonne M. Terry-McElrath, ${ }^{1}$ Patrick M. O'Malley, ${ }^{1}$ \\ and Melanie Wakefield ${ }^{2}$
}

\begin{abstract}
Public health efforts to reduce the harms related to tobacco use currently include a significant emphasis on anti-smoking media campaigns. This paper provides (a) data on the overall extent of exposure to anti-smoking media among American youth from 1997 to 2001, (b) an appraisal of general youth reactions to such advertising, and (c) an examination of how exposure levels and reactions vary by socio-demographic characteristics. Data were obtained from the Monitoring the Future study, an ongoing nationwide study of youth. Data were collected each year from nationally representative separate and nonoverlapping school samples of 8th, 10 th, and 12 th grade students $(N=29,724 ; 24,639$; and 12,138 , respectively). Self-reported levels of recalled exposure to both electronic and print anti-smoking advertising were measured, as well as the judged impact and perceived exaggeration of such advertising. Data indicate that significant increases in overall exposure to anti-smoking advertising occurred over the study time period. These increases were associated with (a) increases in the self-reported likelihood that anti-smoking advertising diminished the probability of individual smoking behaviors, and (b) increases in the perceived level to which anti-smoking advertising exaggerates the risks associated with smoking. Further, these trends were significantly associated with various characteristics-most notably, ethnicity, smoking behaviors, and residence in a state with an ongoing tobacco-control program having a media component.
\end{abstract}

KEY WORDS: anti-smoking advertising; youth smoking; prevention; anti-tobacco; media campaigns.

\section{INTRODUCTION}

Over the last decade, Americans have experienced a dramatic increase in exposure to antismoking media campaigns. Such campaigns are often part of comprehensive programs aimed at discouraging initiation, encouraging smoking cessation, and advocating for the general public's protection from secondhand smoke (Wakefield et al., 2003b, 2003c). These campaigns vary by the audience they target

\footnotetext{
${ }^{1}$ University of Michigan, Ann Arbor, Michigan.

${ }^{2}$ Center for Behavioral Research in Cancer, The Cancer Council Victoria, Carlton, Victoria 3053, Australia.

${ }^{3}$ Correspondence should be directed to Lloyd D. Johnston, $\mathrm{PhD}$, Institute for Social Research, University of Michigan, PO Box 1248, Ann Arbor, Michigan 48106-1248; e-mail: lloydj@umich. edu.
}

(general audiences or youth), the theme of the campaign (e.g., short-term health effects, industry manipulation, and family guidance), executional style, funding (affecting both advertisement production and the extent of air time purchased), and a host of other factors.

Multiple studies have been conducted to evaluate the results of anti-smoking campaigns, with varying results. The largest studies to date have focused on statewide campaigns, such as those in California and Massachusetts. Today, with national anti-smoking advertising campaigns now produced and broadcast by groups such as the American Legacy Foundation, Philip Morris, and Lorillard, there is a need to understand the national reach of such media. However, to date, no study has provided trend data with which to gauge the overall extent of exposure to anti-smoking media among 
youth at a national level, their general reactions to and appraisal of such advertising, and-of critical importance-how such exposure levels and reactions vary by socio-demographic characteristics. This paper aims to provide the public health community with such information.

\section{The Problem of Youth Smoking}

Concerns about the health consequences of tobacco use are now widely known. Public health efforts to reduce the harms related to tobacco use often target adolescents because this group is most likely to take up smoking. A brief summary of youth smoking levels may prove useful in understanding the importance of anti-smoking media efforts. Data from the Monitoring the Future study (Johnston et al., 2002) indicate that after a period of relative stability in the 1980s, current use of cigarettes (use within the past 30 days) began increasing among 8th, 10th, and 12th grade students in the early 1990s. Prevalence rates peaked in 1996 for 8th and 10th graders at 21 and $30 \%$, respectively, while rates for 12 th graders peaked in 1997 at almost $40 \%$. As discussed next, efforts to conduct comprehensive anti-tobacco campaigns intensified in the late 1990s, perhaps contributing to a significant drop in current smoking to rates measured in 2001 of $12 \%$ for 8 th graders, $21 \%$ for 10 th graders, and $30 \%$ for 12 th graders (see Fig. 1).

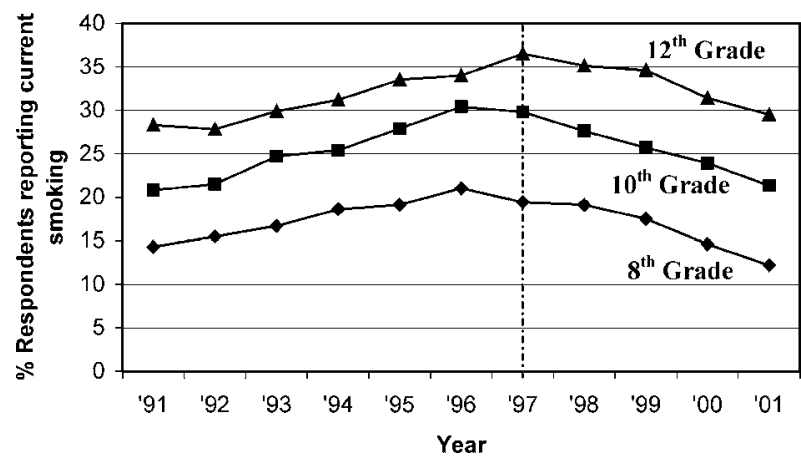

Fig. 1. Current (30-Day) prevalence of cigarette smoking. Dashed line demarcates the beginning of the 1997-2001 time frame used for all analyses included in the current paper. Weighted sample $N$ ranges per year for each grade are as follows: 8th grade 16,23018,$594 ; 10$ th grade $13,612-17,011 ; 12$ th grade $12,983-16,336$.
A (Brief) History of Anti-Smoking Media Activity in the United States ${ }^{4}$

Americans were exposed to significant levels of anti-smoking television media for the first time from 1967 to 1970 . Prior to that point, anti-tobacco public service announcements (PSAs) had been aired on television (usually sponsored by a national voluntary health organization such as the American Cancer Society), but PSAs depended on donated public service time and space and were unable to begin to match the tobacco industry's advertising efforts. Beginning in 1967, the Federal Communication Commission's Fairness Doctrine required licensed television networks to provide relatively equal broadcast time for controversial issues, including tobacco-related advertising. The resulting increased donation of airtime to anti-smoking groups dramatically increased Americans' exposure to anti-smoking messages. Estimates of the actual ratio between the value of anti-smoking and pro-smoking ads aired during this time have been estimated at one to three (Lewit et al., 1981). Studies have documented significant decreases in overall smoking prevalence during the years the doctrine was in place (Lewit et al., 1981; Schneider et al., 1981; Warner, 1977, 1979), including decreases in teen smoking participation (Lewit et al., 1981). After all cigarette advertising was banned from television broadcasting via the 1970 Public Health Cigarette Smoking Act, the requirement to air anti-smoking PSAs also disappeared. While anti-smoking television PSAs certainly did not disappear from American television, broadcast frequency dropped significantly (Warner, 1977).

During the 1980s, several communities participated in scientific trials examining the possible effects of anti-smoking campaigns, either as stand-alone interventions or in conjunction with other programming such as school prevention efforts. ${ }^{5}$ Findings from these studies have varied. While some studies show no influence on youth smoking rates (Bauman et al., 1991; Flay et al., 1988, 1995; Winkelby et al., 1993), decreases in smoking activity have been seen in others (Biglan et al., 2000; Flynn et al., 1992, 1994;

${ }^{4}$ For an in-depth summary of anti-smoking media campaign activity and related findings, please see Pechmann (1997) and Wakefield et al. (2003b, 2003c).

${ }^{5}$ Again, see Pechmann (1997) and Wakefield (2003b, 2003c), for an in-depth summary of anti-smoking media campaign activity and related findings. 
Johnson et al., 1990; Pentz et al., 1989a, 1989b; Perry et al., 1992). A variety of other smoking-related attitudes and behaviors have also been found to be significantly affected by campaigns, including approval of peer smoking (Bauman et al., 1991), knowledge and consequences of smoking, aspects of social resistance, perceived prevalence, and efforts to resist trying cigarettes (Flay et al., 1995). Limitations of these studies include an inability to determine the relative influence of media versus other programming in multicomponent interventions; a lack of subgroup analyses; insufficient levels of media exposure; and inattention to media message content, quality, and targeted audience.

The first statewide anti-smoking media campaign effort was conducted in Minnesota beginning in 1986. Three years later, in 1989, California began the first statewide comprehensive (multicomponent) campaign, followed by Massachusetts in 1994. Arizona began its statewide program in 1996; Florida, Maine, and Oregon began broadcasting in 1998; and Mississippi began its campaign in 1999. By the end of the 2000, additional statewide campaigns were running in Idaho, Minnesota, and Washington. Three nationwide anti-smoking campaigns also began airing during this period: tobacco manufacturer Philip Morris launched its nationwide anti-smoking campaign in late 1998; Lorillard Tobacco Company began airing anti-smoking ads in late 1999; and by February 2000, the American Legacy Foundation began running anti-smoking advertising. Philip Morris reported that it stopped airing its youth-focused "Think. Don't Smoke" campaign in June 2002. The ending of the campaign occurred shortly after the publication of research indicating that the campaign had counterproductive influences on youth attitudes toward smoking (Farrelly et al., 2002). However, Philip Morris continues to air its parent-focused "Talk. They'll Listen" campaign.

Evaluations of the Minnesota program after 4 years showed no significant changes in either smoking-related beliefs or behaviors among adolescents (Murray et al., 1992, 1994). Oregon has shown success in reducing overall smoking compared to national rates, and some success in reducing youth tobacco use (Oregon Department of Human Services, 2003). Massachusetts showed trends indicating a decrease in smoking among youth concurrent with the implementation of the state's anti-smoking campaign (Harris et al., 1996), as well as departures from national trends of increasing youth smoking in the mid- 1990s (Briton et al., 1997). In addition, evaluation of the Massachusetts television campaign showed significant slowing in rates of overall progression to established smoking among youth and more accurate perceptions of youth smoking prevalence among younger adolescents (Siegel \& Biener, 2002).

Both the California and Florida programs have shown strong results when examining youth smoking and related attitudes and beliefs. Early evaluations of the California program, which began in 1989, showed increased aided and unaided recall of the campaign, unfavorable attitudes toward smoking, and decreases in both smoking uptake intentions and actual smoking prevalence (Popham et al., 1994). More recent research has indicated that significant increases in protection from secondhand smoke have also been associated with the campaign (Pierce et al., 2002). Research on the relative impact of California's media campaign as compared with the concurrent increase in state cigarette taxes has also demonstrated that while increased taxes were estimated to be responsible for $78 \%$ of the decrease in cigarette pack sales, the media component of the comprehensive campaign was estimated to be responsible for $22 \%$ (Hu et al., 1995). Research on adult smoking prevalence and consumption (both of which experienced significant decreases early in the campaign) has shown that results did not continue between 1994 and 1996. Theories on why campaign effectiveness on adult smoking prevalence and consumption dropped in later years include changes in campaign expenditure ratios, as well as drops in both premium cigarette prices and levels of grassroots activities against smoking (Pierce et al., 2002). Similar analysis models have not been completed for adolescent smoking.

As part of the evaluation of the Florida Tobacco Pilot Program, media tracking surveys of teenagers demonstrated high rates of campaign awareness and specific ad awareness in the first 6 weeks of the campaign, which persisted to 1 year (Sly et al., 2001a). Over the first year of the campaign in 1998, there were changes in attitudes consistent with the intention of campaign messages, decreases in adolescent intentions to smoke, and decreases in smoking behavior among Florida youth. These decreases were greater than those observed in states with low levels of anti-smoking activity (Sly et al., 2001a). Two-year evaluations showed that baseline nonsmoking youth who, at follow-up, reported high scores on an ad effect index (incorporating ad campaign awareness, receptivity, and perceived influence of the campaign) 
were less likely to initiate smoking than youth with lower scores, and were less likely to become established smokers. Adjusted odds ratios between the ad effect index and measures of initiation and established smoking were similar within categories of age, sex, susceptibility, and parent smoking (Sly et al., 2001b). The evaluations also indicate a dose effect relative to cumulative exposure to anti-tobacco advertising and youth smoking uptake (Sly et al., 2002). In school-based surveys undertaken by the Florida Department of Health, the prevalence of past 30-day cigarette use declined from pre-campaign 1998 to post-campaign 1999 in Florida (Bauer et al., 1999). The decline continued in 2000, with this follow-up study additionally reporting that the percentage of committed nonsmokers significantly increased from 1998 figures (Bauer et al., 2000). The percentage decrease in current smoking reported in the publications of Bauer et al. $(1999,2000)$ shows that the decline in Florida exceeded that observed nationally in the Monitoring the Future study (Johnston et al., 2002). Data on the effects of other state programs are not yet available.

Findings from both community and statewide anti-smoking efforts indicate that media campaigns may be an important component in public health attempts to lower youth smoking rates. Research to date on these campaigns has also indicated important measures that should be included in examinations of anti-smoking media campaigns at the national level.

\section{Theoretical Models and Outcome Measures}

Selection of measures to investigate national anti-smoking media campaign exposure should be grounded in the theory used to drive the development of the campaigns themselves. However, as would be expected, a wide variety of theoretical models have been used in developing the campaigns. In their concise review of the theoretical stages of anti-smoking media development, Logan and Longo (1999) point to three main stages: (a) social learning models that stress the importance of media as a public awareness and informational tool, assisting in value clarification and goal definition; (b) social influence, cognitive behavioral, and life skills models, which position mass media as a supplemental addition to interpersonal interaction, emphasizing problem-solving and decision-making skills; and (c) a combination of approaches that further seeks to better encourage public involvement and account for the social climate affecting individuals, potentially introducing issues of perceived campaign paternalism. The measures discussed in this paper have been selected, in part, to reflect various aspects of these theoretical approaches: (a) recalled exposure to antismoking advertisements (to indicate public awareness); (b) judged impact of such ads (as one aspect of cognitive engagement and decision making); and (c) perceived exaggeration of such ads (to indicate possible negative reactions to ad campaigns).

Some studies have seen no relationship between anti-smoking media exposure and smokingrelated beliefs and/or behaviors (Murray et al., 1994). However, level of recalled exposure to anti-smoking advertising has, in some studies, been associated with increased beliefs of both tobacco industry manipulation and anti-tobacco use opinions (Farrelly et al., 2002), declines in overall smoking prevalence (Mudde \& De Vries, 1999; Popham et al., 1994), and lower rates of progression to established smoking among youth aged 12-13 (Siegel \& Biener, 2000). Research also indicates that exposure may help reduce overestimates of peer smoking, which has been related to increased smoking (Siegel \& Biener, 2000). Significantly, research suggests that exposure is most important for younger youth, such as those in grades 5-10 (McKenna et al., 2000; Pechmann, 1997).

Judged impact of anti-smoking advertising refers to the level to which youth report they think anti-smoking advertising has made them less likely to smoke cigarettes. Although this measure cannot be assumed to predict future behaviors, it is an indication of behavioral intention. Behavioral intentions, together with attitudes and normative beliefs, have been found to be important indicators of changes in smoking rates and status (Pechmann, 1997; Pierce et al., 1996; Smith \& Stutts, 1999). Further, initial research indicates that affective reactions toward antismoking media campaigns, as well as discussion of the campaigns, may predict decreased smoking initiation and increased cessation (Biener \& Taylor, 2002; Hafstad et al., 1997).

Perceptions of the extent to which youth believe that anti-smoking advertisements exaggerate the risks associated with smoking can be viewed in two ways. Perceived exaggeration may indicate that campaigns could cause negative reactions due to paternalistic portrayals of smoking-related harms. Hill et al. (1998) have suggested that a significant communication challenge in anti-smoking campaigns is to somehow translate scientific knowledge into "felt experience, vs. a cognitive appreciation of risk" 
(p. 6). However, they also note that campaigns may be more successful in portraying definite short-term consequences than dire, long-term consequences. Interestingly, as Hafstad et al. (1997) state, mass communication theory may indicate that use of highly emotional appeals may be most appropriate when the target audience has low interest in the subject matter or when the available information is considered "old news." They note, "provocative and dissonance arousing appeals that create affective reactions and lead to interpersonal communication should be given more attention in campaigns designed to influence adolescent smoking. However, such appeals may easily produce negative reactions and the normative context should be thoroughly considered when using such appeals in future interventions" (p. 227).

Research indicates that anti-smoking media campaigns play a significant role in efforts to reduce smoking. This paper provides an overview of the national trends among youth - the primary target audience in most such campaigns - in recall and appraisal of anti-smoking campaigns from 1997 to 2001 . These trends will also be examined for socio-demographic differences.

\section{METHODS}

Data used in this paper were obtained from the Monitoring the Future study, an ongoing nationwide study of youth conducted by the Institute for Social Research (ISR) under a series of research grants from the National Institute on Drug Abuse. While a detailed description of study design and procedures can be found elsewhere (Bachman et al., 2001), the following provides a brief summary of the samples, survey methods, measures, and analysis models used for the present analyses.

\section{Sample Description and Data Collection Methods}

From 1997 to 2001, data were collected each year from separate and nonoverlapping school samples of 8th, 10th, and 12th grade classes drawn so as to be representative of all students in the specified grade for the 48 contiguous states. All surveys were self-completed and group administered within school settings by ISR personnel, and data collection protocols remained consistent over time. From 1997 to 2001, either an original selection school or a replacement school (matched to the original in terms of size, geographic area, urbanicity, etc.) was surveyed in $98 \%$ of the sample units $(55 \%$ original, $43 \%$ replacement). Student response rates averaged $89 \%$ for 8 th, $86 \%$ for 10 th, and $83 \%$ for 12 th grade surveys. Student nonresponse was almost entirely accounted for by absenteeism. Obtained total sample sizes used in the current analyses (summing over the 5 years) were 29,724 8th graders; 24,639 10th graders; and 12,138 12th graders. These numbers represent students responding to forms containing antismoking media items: two of the four 8th and 10th grade survey forms, and one of the six 12 th grade survey forms.

\section{Measures}

Measures used in the present analyses include exposure to anti-smoking media, appraisal of such media, student socio-demographics, smoking behaviors, and reported media consumption.

\section{Measures Related to Anti-Smoking Media}

Three measures related to anti-smoking media were used in these analyses: (a) recalled exposure, (b) judged impact, and (c) perceived exaggeration. For recalled exposure to print- and electronic-format ads, the following text was used: "The next questions are about anti-smoking commercials or 'spots' that are intended to discourage cigarette smoking. In recent months, (a) about how often have you seen such anti-smoking commercials on TV or heard them on the radio?; (b) about how often have you seen anti-smoking ads on billboards or in magazines and newspapers?" A six-point answer scale was provided, ranging from "not at all" to "more than once a day." Dichotomies were created from these scales: weekly or higher exposure, and less than weekly exposure. For both judged impact and perceived exaggeration, students responded to the following question: "To what extent do you think such ads on TV, radio, billboards, or in magazines and newspapers have (a) made you less likely to smoke cigarettes?; (b) overstated the dangers or risks of cigarette smoking?" A five-point answer scale ranging from "not at all" to "to a very great extent" was provided, and a dichotomy was created for each item for "to some extent" or more, versus "not at all" or "to a little extent." 


\section{Student Socio-Demographics}

A variety of socio-demographic measures was included in these analyses that, based on findings in the literature, are related to smoking behavior differences. Except for state of residence, these measures are all student self-reported data: student ethnicity (White, African American, Hispanic, and other), gender, average academic grades (dichotomized into D to B- vs. B to A), likelihood of graduating from a 4-year college (dichotomized into definitely will vs. other), a composite of parental educational level used as a proxy for family socioeconomic status (trichotomized into low, medium, and high), and residence in a tobacco-control state. "Tobacco-control states" were defined as states with a statewide comprehensive media campaign in effect at least 2 months prior to data collection. If a state started its media campaign less than 2 months before the survey was administered to students in that state, it is unlikely that youth in that state would have seen the ads. Therefore, in such cases, the data were moved to "missing" and not included in the analyses $(N=664$, or $1 \%$ of the total cases). Specifically, the following states were classified as tobacco-control states: (a) Arizona, California, and Massachusetts from 1997 to 2001; (b) Florida, Maine, and Oregon from 1999 to 2001; (c) Mississippi from 2000 to 2001; and (d) Idaho, Minnesota, and Washington for 2001.

\section{Smoking Behaviors}

Two smoking-related behavior measures were utilized: past 30-day smoking (trichotomized into none, less than daily, and daily or more often), and 5 -year smoking intentions (dichotomized into definitely will not be smoking vs. other).

\section{Media Consumption Variables}

General media consumption variables are briefly discussed only to provide context for overall youth media exposure that may have included anti-smoking ads. Consumption variables included watching television, listening to the radio, reading magazines and newspapers, and using a computer (both school- and nonschool-related use). These measures are not available on the same question- naire forms as the anti-smoking media exposure and appraisal measures. Thus, for general media consumption measures, sample sizes are not the same as those for other measures. In addition, to provide a stronger time context, all media consumption variables except for computer use include data from 1991 to 2001. (Computer use measures were added only in 1997.) Specifically, weighted sample sizes range from 22,222 to 197,462 for 8th grade; 21,530 to 167,691 for 10 th grade; and 9,998 to 27,933 for 12 th grade.

For television viewing, students were asked, "How much TV do you estimate you watch on an average weekday?"; for listening to the radio (not available for 12th graders), students were asked, "How many hours do you estimate that you spend listening to the radio on an average day?" Answer categories were a seven-point scale ranging from none to $5 \mathrm{hr}$ or more. Dichotomies were created contrasting "about $2 \mathrm{hr}$ to $5 \mathrm{hr}$ or more" versus "other." For both magazine and newspaper consumption, students were asked, "How often do you do each of the following?" with "read magazines" and "read newspapers" as separate response items. Answer categories were a five-point scale ranging from "never" to "almost every day." Dichotomies were created contrasting "at least once a week" or more versus "other." Finally, for computer use, students were asked, "About how many hours a week do you spend using a computer (a) doing school work?, and (b) doing other things?" Answer categories used a seven-point scale ranging from "none" to " 20 or more;" dichotomies were created contrasting "6-9 hr" or more versus "other."

\section{Analysis Models}

The purpose of the analyses was to inform discussion of the efficacy of anti-smoking media campaigns within the United States by exploring the reported exposure to and appraisal of such advertising by American youth at the national level; thus, the analysis models utilized were primarily descriptive in nature. All analyses were conducted using SAS v.8, including weights to account for the multistage sampling procedures. Bivariate models were specified utilizing Pearson's chi-square in PROC FREQ; multivariate models were run using PROC LOGISTIC. Design effects were estimated using IVEware (Raghunathan et al., 2002) for both media consumption time trend analyses and bivariate 
and multivariate analyses (on anti-smoking advertising recalled exposure, judged impact, and perceived exaggeration). On the basis of the resulting design effect estimates, all reported significance levels were adjusted to account for the increased variance attributable to sampling procedures.

\section{RESULTS}

After a brief description of the sample used in this paper, a synopsis of general media consumption trends is provided as context for the levels of anti-smoking advertising exposure in both electronic and print media. Rates of national recalled exposure to anti-smoking ads are then presented, followed by judged impact of such advertising and then perceived exaggeration. Within each section, findings on observed socio-demographic variation are documented.

\section{Sample Description}

Characteristics of the samples obtained are described in Table 1 (presented by grade with years combined). Briefly, the combined sample of 8th, 10th, and 12th grade students was roughly equally distributed by gender and included $72 \%$ White. Average grades of B or higher were reported by $63 \%$, and almost $60 \%$ indicated they definitely planned to graduate from college. Students reporting either low or medium parental education levels made up $44 \%$ of the sample. While $57 \%$ stated they definitely would not be smoking 5 years from the time of the survey, $26 \%$ reported some level of cigarette smoking over the past 30 days. Twenty percent of students resided in states with comprehensive tobacco-control campaigns, including a media component.

\section{General Media Consumption}

As expected, media consumption rates varied based on both grade and type of medium. As illustrated in Table 2, 8th graders had the highest media consumption rates of both television (watching 2 or more hr per day) and magazines (reading weekly or more often), at 73.1 and $54.2 \%$, respectively. In contrast, they had the lowest consumption rates of both radio (listening 2 or more hr per day) and newspapers (reading weekly or more often). Tenth graders had slightly higher radio consumption at $55.7 \%$, while

Table 1. Sample Description, 1997-2001 ${ }^{a}$

\begin{tabular}{lccc}
\hline & $\begin{array}{c}\text { \% 8th Grade } \\
(N=29,724)\end{array}$ & $\begin{array}{c}\text { \% 10th Grade } \\
(N=24,639)\end{array}$ & $\begin{array}{c}\% \text { 12th Grade } \\
(N=12,138)\end{array}$ \\
\hline Male & 48.7 & 48.4 & 48.4 \\
Ethnicity & & & \\
$\quad$ White & 68.6 & 73.4 & 74.6 \\
$\quad$ African American & 17.0 & 13.2 & 14.0 \\
$\quad$ Hispanic & 14.4 & 13.4 & 11.4 \\
Average grade of B or higher & 64.1 & 58.2 & 66.9 \\
Definitely plan on graduating & 60.7 & 57.3 & 55.7 \\
$\quad$ from college & & & \\
Parental education & 14.3 & 15.0 & 13.7 \\
$\quad$ Low & 28.6 & 29.9 & 30.8 \\
$\quad$ Medium & 57.1 & 55.1 & 55.5 \\
$\quad$ High & & & 67.1 \\
Past 30-day smoking & 82.8 & 73.6 & 11.8 \\
$\quad$ None & 9.5 & 10.8 & 21.1 \\
$\quad$ Less than daily & 7.7 & 15.5 & 59.3 \\
$\quad$ Daily or more often & 54.0 & 57.7 & 17.3 \\
Definitely do not intend & & & \\
$\quad$ to be smoking in 5 years & 19.7 & 22.8 & \\
Reside in state with & & & \\
$\quad$ tobacco-control program & &
\end{tabular}

${ }^{a}$ Data presented by grade with years combined. 
Table 2. General Media Consumption Rates ${ }^{a}$

\begin{tabular}{|c|c|c|c|c|c|}
\hline Type of media & $\begin{array}{c}2001 \\
\text { Rates }\end{array}$ & $\begin{array}{l}\text { 10-year change: } \\
2001 \text { minus } 1991\end{array}$ & $p$ & $\begin{array}{l}\text { 4-year change: } \\
2001 \text { minus } 1997\end{array}$ & $p$ \\
\hline \multicolumn{6}{|c|}{ Television: $\%$ watching $2+\mathrm{hrs} /$ day } \\
\hline 8th Grade & 73.1 & -6.5 & $* * *$ & -2.7 & \\
\hline 10th Grade & 64.3 & -7.2 & $* * *$ & -3.0 & \\
\hline 12th Grade & 55.8 & -6.1 & * & -3.0 & \\
\hline \multicolumn{6}{|l|}{ Radio: \% listening $2+\mathrm{hrs} / \mathrm{day}^{b}$} \\
\hline 8th Grade & 53.7 & -7.3 & $* * *$ & -3.8 & $* * *$ \\
\hline 10th Grade & 55.7 & -9.4 & $* * *$ & -5.4 & *** \\
\hline \multicolumn{6}{|c|}{ Newspapers: \% reading weekly or more } \\
\hline 8th Grade & 35.8 & -24.1 & $* * *$ & -8.9 & $* * *$ \\
\hline 10th Grade & 46.0 & -22.0 & $* * *$ & -8.8 & $* * *$ \\
\hline 12th Grade & 52.1 & -19.6 & $* * *$ & -11.5 & $* * *$ \\
\hline \multicolumn{6}{|c|}{ Magazines: \% reading weekly or more } \\
\hline 8th Grade & 54.2 & -9.5 & $* * *$ & -5.8 & $* * *$ \\
\hline 10th Grade & 49.5 & -10.7 & $* * *$ & -4.9 & $* *$ \\
\hline 12th Grade & 45.7 & -8.6 & $* *$ & -4.3 & \\
\hline \multicolumn{6}{|l|}{$\begin{array}{l}\text { School-related computer use: } \\
\quad \% \text { using } 6+{\text { hrs } / \text { week }^{c}}^{\text {a }}\end{array}$} \\
\hline 8th Grade & 6.8 & - & & 0 & \\
\hline 10th Grade & 6.6 & - & & -0.2 & \\
\hline 12th Grade & 9.9 & - & & -1.7 & \\
\hline \multicolumn{6}{|l|}{$\begin{array}{l}\text { Nonschool-related computer use: } \\
\text { \% using } 6+\text { hrs/week }^{c}\end{array}$} \\
\hline 8th Grade & 30.9 & - & & +13.6 & $* * *$ \\
\hline 10th Grade & 29.3 & - & & +15.9 & $* * *$ \\
\hline 12th Grade & 30.3 & - & & +15.2 & *** \\
\hline \multicolumn{6}{|c|}{$\begin{array}{l}{ }^{a} \text { Weighted sample } \mathrm{N} \text { ranges per year per item are as follows: Television } 8 \text { th grade } 16,649-18,907 ; 10 \text { th } \\
\text { grade } 13,797-17,182 ; 12 \text { th grade } 2,167-2,773 \text {. Radio } 8 \text { th grade } 16,627-18,908 ; 10 \text { th grade } 13,779-17,143 \text {. } \\
\text { Newspapers } 8 \text { th grade } 16,570-18,840 ; 10 \text { th grade } 13,754-17,080 ; 12 \text { th grade } 2,203-2,829 . \text { Magazines } 8 \text { th } \\
\text { grade } 17,121-18,920 ; 10 \text { th grade } 13,785-17,164 ; 12 \text { th grade } 2,209-2,827 \text {. School-related computer } 8 \text { th grade } \\
\text { 4,231-4,697; } 10 \text { th grade } 4,111-4,617 ; 12 \text { th grade } 1,832-2,213 \text {. Nonschool-related computer } 8 \text { th grade } 4,193- \\
4,662 ; 10 \text { th grade } 4,066-4,584 ; 12 \text { th grade } 1,820-2,197 \text {. } \\
{ }^{b} \text { Daily radio consumption not available for } 12 \text { th grade students. } \\
{ }^{c} \text { Measured from } 1997 \text { forward. } \\
{ }^{*} p<.05 .{ }^{* *} p<.01 .{ }^{* * *} p<.001 \text {. }\end{array}$} \\
\hline
\end{tabular}

12th graders were clearly the most likely to read newspapers weekly or more often, at $52.1 \%$. While school-related computer use was relatively low for all three grades (ranging from 6.8 to $9.9 \%$ ), nonschoolrelated use of computers was fairly consistent for all three grades at approximately $30 \%$. As to media consumption rates over time, newspaper consumption showed significant declines in consumption rates for all three grades, averaging a $21.9 \%$ decline over just the past 10 years. Not surprisingly, nonschoolrelated computer use moved in the opposite direction, averaging a $14.9 \%$ increase since 1997 . These findings indicate that, strictly as a function of overall consumption, television is the medium most likely to reach youth with anti-smoking advertising; however, a clear difference in consumption between younger and older grades is evident with this medium. News- papers are least likely to reach a young audienceespecially in the lower grades.

\section{Anti-Smoking Advertising Recalled Exposure: Electronic and Print Media}

\section{Time Trends in Recalled Exposure}

As Fig. 2 illustrates, reported levels of recalled exposure to anti-smoking ads in both electronic (television and radio) and print (billboards, magazines, and newspapers) media increased significantly from 1997 to 2001. By 2001, the percentage of students reporting that they recalled at least weekly exposure to anti-smoking ads on television or radio over the past several months reached almost two-thirds: 


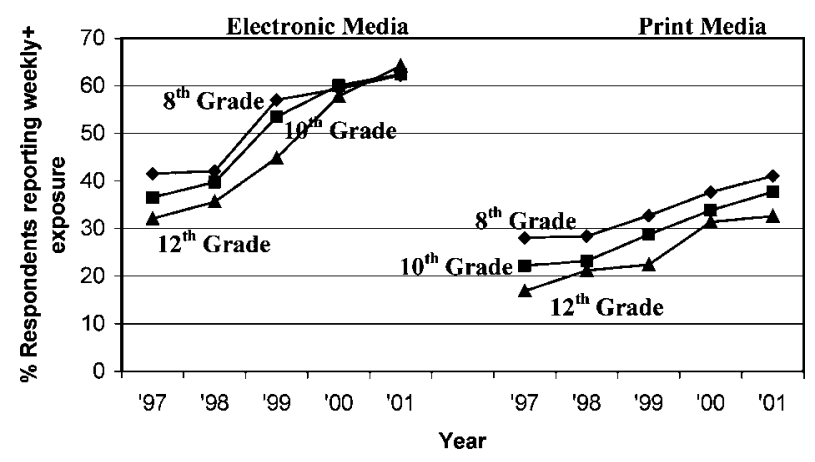

Fig. 2. Recalled exposure to anti-smoking advertising in electronic and print media. Weighted sample $N$ ranges per year for electronic media recall are 8th grade 5,126-5,692; 10th grade 4,473-5,029; 12 th grade $2,048-2,485$. Sample $N$ s for print media recall are 8 th grade $5,121-5,686 ; 10$ th grade $4,464-5,024 ; 12$ th grade $2,049-2,481$.

$62.3 \%$ for 8 th grade, $62.5 \%$ for 10 th grade, and $64.2 \%$ for 12th grade. While 2001 data indicated that students in all grades recalled equal exposure, this was not the case during earlier years. In 1997, only $32.1 \%$ of 12 th graders reported such exposure, compared with $41.5 \%$ of 8 th graders. The overall mean increase in recalled exposure to electronic anti-smoking ads was $26.2 \%$.

An examination of the construct validity of the recalled exposure measure for electronic antismoking advertising can be seen in Fig. 3. In this figure, individual trend lines for recalled exposure are provided for states, grouped according to when (or if) states began comprehensive anti-tobacco media campaigns. The first state grouping (Arizona, California, and Massachusetts) shows significantly higher levels of recall than other state groupings for the first 2 years; these states all had active media campaigns from the beginning of the time period included in this study. The second grouping (Florida, Maine, Oregon, and Mississippi) is comprised of states that began their campaigns in either 1999 or 2000. A clear increase in levels of recalled exposure for these states began in 1999, and the resulting high level of recall was sustained for the remainder of the study. Nontobacco control states show an increasing level of recall starting in 1999, matching with the beginning of the Philip Morris campaign. However, the degree of increase is not as strong as that observed for those states starting their own campaigns in 1999. Finally, the third grouping of states (those with campaigns beginning in 2001Idaho, Minnesota, and Washington) also reported
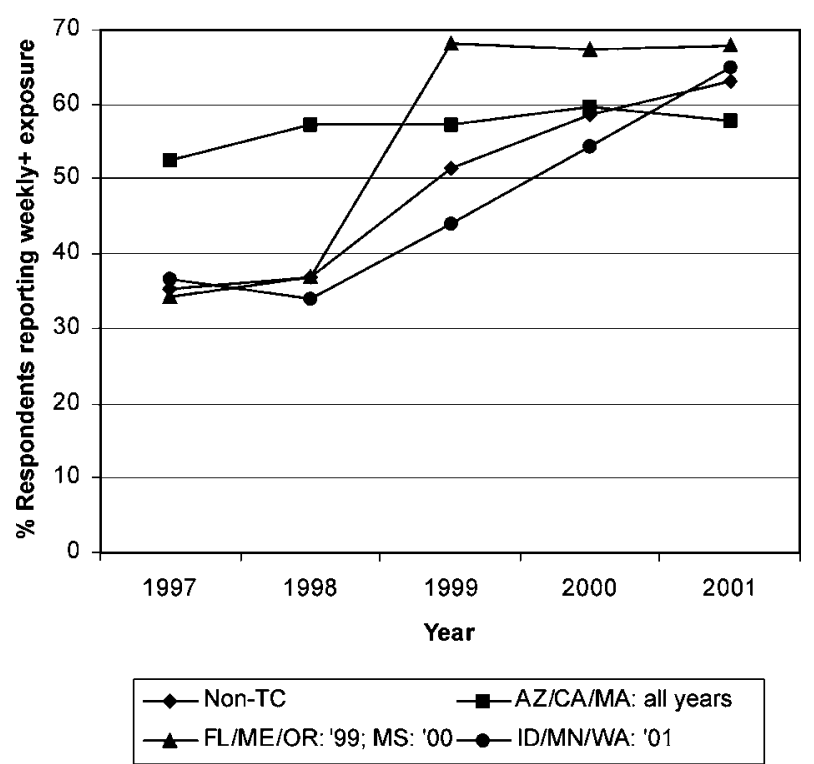

Fig. 3. Recalled exposure to electronic anti-smoking ads by the timing of state-level media campaigns, all grades. Weighted sample $N$ ranges per year for each group are as follows: Non-TC (or nontobacco-control states) 8,538-9,574; AZ/CA/MA 1,680-2,137; FL/ME/OR/MS 838-1,084; ID/MN/WA 368-760. AZ/CA/MA had tobacco-control programs throughout the study as noted in the key; FL/ME/OR began to be classified as tobacco-control states in 1999 and MS in 2000; ID/MN/WA are coded as tobacco-control states in 2001.

increased levels of recalled exposure starting in 1999 and continuing through 2001. However, the levels of recalled exposure for these three states remained lower than other state groupings (including nontobacco control states) until 2001, when recalled exposure rates surpassed those of both nontobacco control states and those states with campaigns throughout the duration of this study (Arizona, California, and Massachusetts).

Regarding print anti-smoking advertising recalled exposure (Fig. 2), overall lower exposure levels and less congruence occurred between the three grades (as compared with electronic media). Data for 2001 show that $41.1 \%$ of 8 th graders, $37.8 \%$ of 10 th graders, and $32.6 \%$ of 12 th graders reported seeing anti-smoking advertising in print media on a weekly basis (or more often). These numbers represent a mean increase of $14.8 \%$ from 1997 levels $(28.1 \%$ for 8 th grade, $22.2 \%$ for 10 th grade, and only $16.9 \%$ for 12 th grade). Interestingly, these increases occurred while overall consumption of print media decreased, as previously discussed. 
The two measures of anti-smoking advertising exposure were highly correlated. Product moment correlations between electronic and print media ad exposure were .50 for both 8 th and 10th grades, and .54 for 12 th grade.

\section{Socio-Demographic Effects on Recalled Exposure}

Extent of recalled exposure to both electronic and print anti-smoking advertising was examined relative to a variety of independent variables that the literature indicates may be related to youth smoking levels: gender, ethnicity, parental education, grades, college plans, current smoking, 5-year smoking intentions, residence in a tobacco-control state, and time. Bivariate analyses (using chi-square) were run with both electronic and print recalled exposure for each of the independent variables listed here. Multivariate analyses (using logistic regression) were run for all variables excluding 5-year smoking intentions. Smoking intentions were not included due to significant overlap with current smoking behavior (i.e., nonsmokers are all included in those who definitely do not plan on smoking in 5 years). By including only smoking behavior, the ease of interpreting the findings was significantly enhanced. Residence in a tobacco-control state and year of study were highly interrelated. Thus, dummy variables were created for year (with 1997 as the excluded, referent category), and interaction terms were then created with the resulting dummies and the dichotomous tobaccocontrol state variable. Results are discussed subsequently (see Tables 3 and 4).

After controlling for all included sociodemographic characteristics, the only variables that were significantly related to electronic antismoking advertising recalled exposure for all grades were tobacco-control state and year. Students living in states with tobacco-control programs reported significantly higher odds of anti-smoking ad recall than those living in nontobacco control states. This effect was most marked for 12th grade students. Only $43 \%$ of 12 th grade students in nontobacco control states recalled seeing anti-smoking advertising on television or hearing it on the radio weekly or more often. In contrast, $61 \%$ of 12 th grade students in tobacco-control states recalled such levels of anti-smoking ads. Levels of recall were also higher in 1999-2001 than at the beginning of the study. The interaction of tobacco-control states and year also showed significance for all grades in 2001, with a decreasing level of odds of recall. This indicates that the effect of residence in tobacco-control states on electronic ad recall decreased in the last year of the study, likely due to the increase of anti-smoking advertising at the national level that increased recall in nontobacco control states.

Additional relationships were observed for ethnicity, grades, and 30-day smoking levels. Although these relationships were not constant for all three grades in the study, at least two grades showed such results. Among 10th and 12th graders, significantly higher recall of electronic ads was reported among African American students (vs. White students), and daily smokers (vs. nonsmokers). Students reporting average grades of B and higher were also more likely to recall such ads, but only among 8th and 10th graders.

Results from the multivariate analyses focusing on recalled exposure to print anti-smoking ads (see Table 4) indicated that ethnicity, current smoking levels, tobacco-control states, and year were all significantly related to recall, and for all three grades. After controlling all socio-demographic variables, both Hispanic and African American students had higher odds of recalled exposure for all grades compared with White students (odds ratios [ORs] of 1.21.3 for Hispanics and 1.5-1.8 for African Americans). Students who reported smoking daily or more often within the past 30 days also reported higher odds of recalled exposure compared with nonsmoking students (ORs of 1.3 for all grades). Again, students living in states with tobacco-control programs reported significantly higher odds of print anti-smoking ad recall than those living in nontobacco control states (ORs of 1.4-1.8), and those responding to the 19992001 surveys versus 1997.

As was the case with electronic ad recall, 10th and 12th grade females reported significantly lower levels of print ad recall than males (ORs of 0.8-0.9). However, while 8th and 10th grade students with higher grades reported increased recall of electronic ads, 10th and 12th grade students with higher grades reported lower recall of print anti-smoking ads (ORs of 0.8-0.9) than those reporting a B-average or less. In contrast to recall for electronic ads, no consistent interaction effect between tobacco-control states and year was observed for print ad recall.

Judged Impact of Anti-Smoking Advertising

\section{Time Trends in Judged Impact}

There were significant differences between grades in student responses to whether the 
Table 3. Socio-Demographic Differences in Weekly + Recalled Exposure to Anti-Smoking Advertising: Electronic Media, 1997-2001 ${ }^{a}$

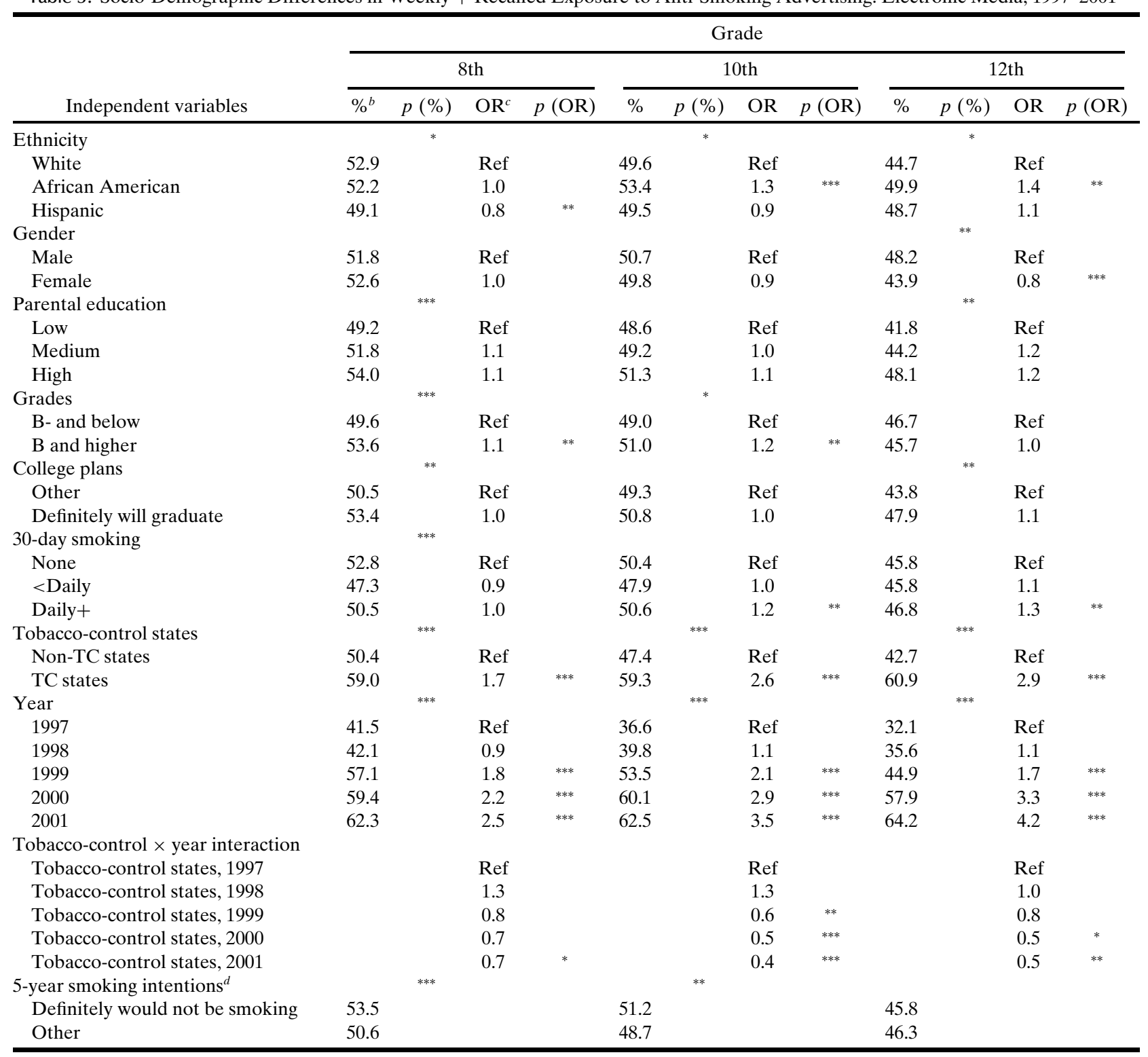

${ }^{a}$ Model $N$ is 19,591 for 8 th grade; 19,032 for 10 th grade; and 9,212 for 12th grade.

${ }^{b}$ Percent respondents per grade reporting weekly + exposure.

${ }^{c}$ Multivariate model odds ratio.

${ }^{d}$ Multivariate models do not include 5-year smoking intentions.

${ }^{*} p<.05 .{ }^{* *} p<.01 .{ }^{* * *} p<.001$.

anti-smoking ads they had seen had made them less likely to smoke (see Fig. 4). In 2001, 8th grade students were not only the most likely to say the ads had had at least some impact in this area $(58.7 \%)$ but also showed the strongest increase over the 5 years of data collection (starting at $44.2 \%$ in 1997 , and ending at $58.7 \%$ in 2001 , an increase of 14.5 percentage points). In contrast, 2001 levels were
$44.9 \%$ for 10th grade students (a 10.0 percentage point increase from 1997) and $38.3 \%$ for 12 th grade students (a 9.2 percentage point increase from 1997).

The construct validity of the judged impact measure can be seen in Fig. 5. In this figure, individual trend lines for the percentage of respondents reporting some or more impact are provided for states, grouped according to when (or if) 
Table 4. Socio-Demographic Differences in Weekly + Recalled Exposure to Anti-Smoking Advertising: Print Media, 1997-2001 ${ }^{a}$

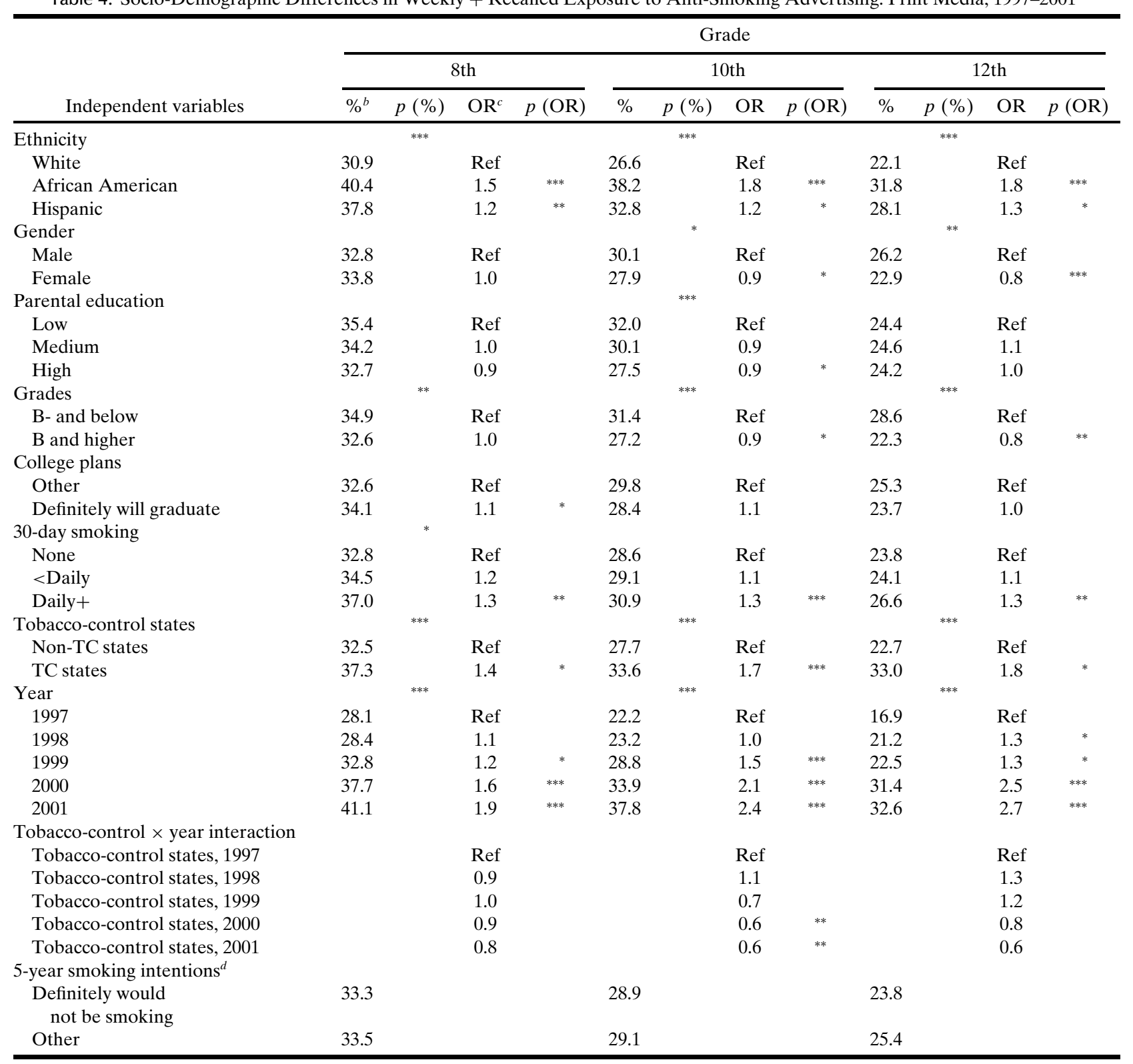

${ }^{a}$ Model $N$ is 19,565 for 8th grade; 19,019 for 10th grade; and 9,199 for 12th grade.

${ }^{b}$ Percent respondents per grade reporting weekly + exposure.

${ }^{c}$ Multivariate model odds ratio.

${ }^{d}$ Multivariate models do not include 5-year smoking intentions.

${ }^{*} p<.05 .{ }^{* *} p<.01 .{ }^{* * *} p<.001$.

they began comprehensive anti-tobacco media campaigns. As with the recalled exposure measure, those states with ongoing media campaigns throughout the study (Arizona, California, and Massachusetts) show significantly higher levels of impact than other state groupings for the first 2 years. The Florida/Maine/Oregon/Mississippi grouping (states that began their campaigns in either 1999 or 2000) shows a clear increase in levels of judged impact beginning in 1999. Interestingly, no increase in judged impact for nontobacco control states is observed until 2000. This suggests that no significant increase in judged impact was associated with the Philip Morris campaign (which began in late 1998). The observed 


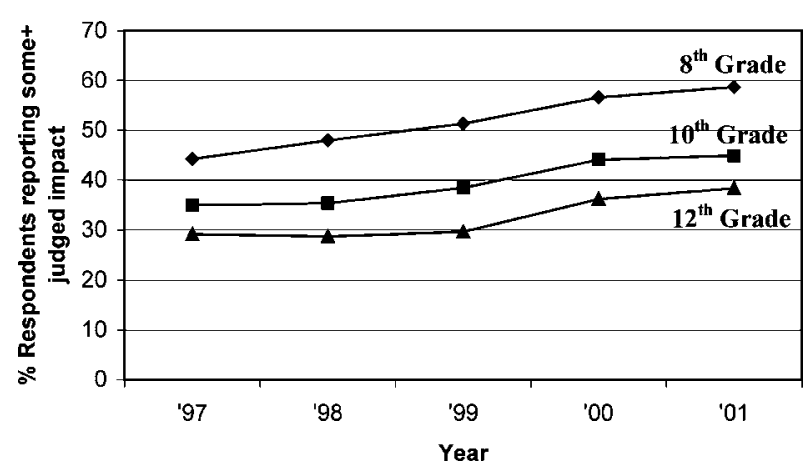

Fig. 4. Judged impact of anti-smoking advertising. Weighted sample $N$ s per year for judged impact are 8 th grade $5,018-5,527 ; 10$ th grade $4,405-4,961 ; 12$ th grade $2,017-2,455$.

increases in judged impact for nontobacco control states in 2000 could be associated with both the American Legacy Foundation and Lorillard campaigns. However, because the ratio of national potential exposure for the American Legacy Foundation campaign ads was more than 100:1 when compared with the Lorillard campaign ads during the first

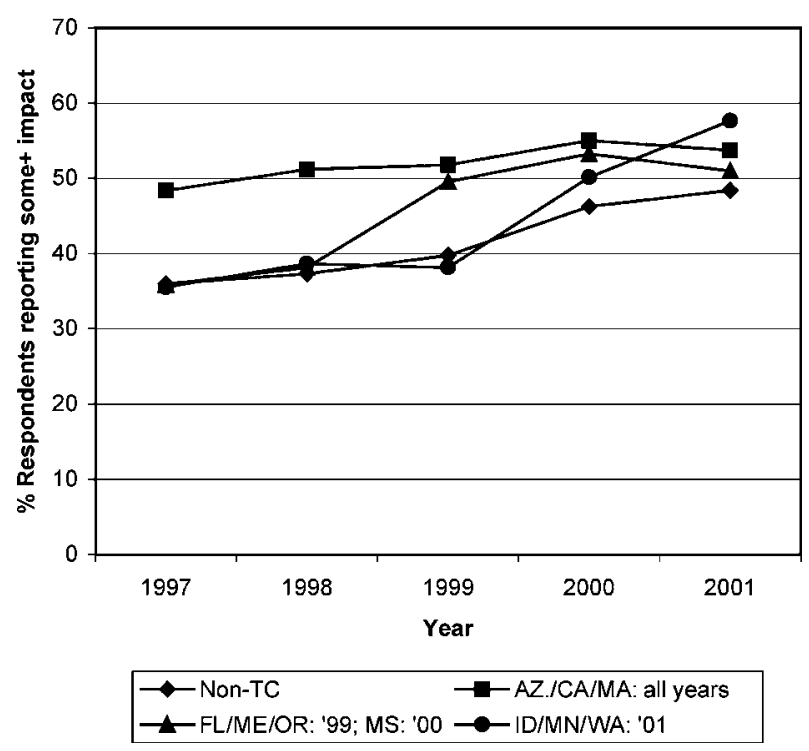

Fig. 5. Judged impact of anti-smoking ads by the timing of state-level media campaigns, all grades. Weighted sample $N$ ranges per year for each group are as follows: NonTC (or nontobacco-control states) 8,695-11,016; AZ/CA/MA 1,639-2,090; FL/ME/OR/MS 824-1,065; ID/MN/WA 357-743. AZ/CA/MA had tobacco-control programs throughout the study as noted in the key; FL/ME/OR began to be classified as tobaccocontrol states in 1999 and MS in 2000; ID/MN/WA are coded as tobacco-control states in 2001.
5 months of 2000 (Glen Szczypka, personal communication, February 18, 2003), the observed proportionate increase in judged impact is vastly more likely to be associated with the American Legacy Foundation campaign.

\section{Socio-Demographic Variation in Judged Impact}

Socio-demographic variation was examined using the same variables as were used for recalled ad exposure, as well as incorporating level of recalled exposure to both electronic and print anti-smoking advertising. Results are shown in Table 5.

For all grades, increased odds of reporting some or more judged impact of anti-smoking advertising were found for females versus males (ORs 1.2-1.3), those reporting weekly or greater recalled exposure to both print (ORs 1.4-1.5) and electronic (ORs 1.5) advertising versus less exposure, and those in 2001 versus 1997 (1.3-1.5). However, decreased odds of higher reported anti-smoking advertising impact were found among those reporting any level of smoking during the past 30 days (ORs $0.3-0.5$ for less than daily smoking and $0.1-0.2$ for daily smokers). It should be noted that although any level of smoking involvement decreased the odds of reported impact, there also is variation among the levels of smoking involvement. Students who reported daily smoking reported significantly lower odds of judged impact than did nondaily smokers (OR 0.4 for 8 th, 10 th, and 12 th grades; not shown in Table 5).

Relationships showing significant results for at least two grades include ethnicity, college plans, and residence in a tobacco control state. Both African Americans and Hispanics reported being impacted by anti-smoking ads more than Whites among 10th and 12th graders (ORs 1.2-1.8). For 8th and 10th graders, those definitely planning on graduating from college also reported being more greatly impacted by ads (ORs 1.2-1.3). Eighth and tenth graders living in states with tobacco control programs also reported higher odds of judged impact (ORs 1.5-1.7).

\section{Perceived Exaggeration of Anti-Smoking Advertising}

\section{Time Trends in Perceived Exaggeration}

While 8th grade students indicated that they felt anti-smoking advertising had more of a judged impact on their future smoking, they were also more likely to report believing that such ads overstated the dangers or risks of cigarette smoking 
Table 5. Socio-Demographic Differences in Some + Judged Impact of Anti-Smoking Advertising, 1997-2001 ${ }^{a}$

\begin{tabular}{|c|c|c|c|c|c|c|c|c|c|c|c|c|}
\hline \multirow[b]{3}{*}{ Independent variables } & \multicolumn{12}{|c|}{ Grade } \\
\hline & \multicolumn{4}{|c|}{8 th } & \multicolumn{4}{|c|}{ 10th } & \multicolumn{4}{|c|}{ 12th } \\
\hline & $\%^{b}$ & $p(\%)$ & $\mathrm{OR}^{c}$ & $p(\mathrm{OR})$ & $\%$ & $p(\%)$ & OR & $p(\mathrm{OR})$ & $\%$ & $p(\%)$ & OR & $p(\mathrm{OR})$ \\
\hline Ethnicity & & $*$ & & & & *** & & & & *** & & \\
\hline White & 50.8 & & Ref & & 35.2 & & Ref & & 27.3 & & Ref & \\
\hline African American & 54.6 & & 1.1 & & 54.0 & & 1.8 & $* * *$ & 46.5 & & 1.8 & $* * *$ \\
\hline Hispanic & 50.4 & & 1.0 & & 46.2 & & 1.2 & ** & 42.2 & & 1.5 & **** \\
\hline Gender & & *** & & & & $* * *$ & & & & $* * *$ & & \\
\hline Male & 48.5 & & Ref & & 37.1 & & Ref & & 29.5 & & Ref & \\
\hline Female & 54.5 & & 1.3 & $* * *$ & 41.6 & & 1.2 & *** & 34.4 & & 1.3 & $* * *$ \\
\hline Parental education & & $* * *$ & & & & & & & & & & \\
\hline Low & 47.2 & & Ref & & 40.8 & & Ref & & 33.3 & & Ref & \\
\hline Medium & 51.4 & & 1.0 & & 39.5 & & 1.0 & & 32.2 & & 1.1 & \\
\hline High & 53.1 & & 0.9 & & 39.1 & & 0.8 & * & 31.8 & & 1.0 & \\
\hline Grades & & $* * *$ & & & & $* * *$ & & & & $*$ & & \\
\hline B- and below & 43.7 & & Ref & & 35.9 & & Ref & & 30.2 & & Ref & \\
\hline $\mathrm{B}$ and higher & 55.9 & & 1.2 & $* * *$ & 41.9 & & 1.1 & & 33.1 & & 1.1 & \\
\hline College plans & & *** & & & & *** & & & & $* *$ & & \\
\hline Other & 44.8 & & Ref & & 34.7 & & Ref & & 29.8 & & Ref & \\
\hline Definitely will graduate & 56.0 & & 1.3 & $* * *$ & 43.0 & & 1.2 & *** & 33.7 & & 1.0 & \\
\hline 30-day smoking & & *** & & & & *** & & & & *** & & \\
\hline None & 57.9 & & Ref & & 47.7 & & Ref & & 39.6 & & Ref & \\
\hline$<$ Daily & 25.8 & & 0.3 & $* * *$ & 23.0 & & 0.3 & $* * *$ & 24.3 & & 0.5 & *** \\
\hline Daily+ & 13.0 & & 0.1 & $* * *$ & 11.0 & & 0.1 & *** & 12.0 & & 0.2 & *** \\
\hline Tobacco-control states & & $* * *$ & & & & $* * *$ & & & & $* * *$ & & \\
\hline Non-TC states & 49.8 & & Ref & & 36.8 & & Ref & & 29.5 & & Ref & \\
\hline TC states & 59.0 & & 1.5 & $* *$ & 48.4 & & 1.7 & $* * *$ & 43.9 & & 1.5 & \\
\hline Year & & *** & & & & **** & & & & **** & & \\
\hline 1997 & 44.2 & & Ref & & 35.0 & & Ref & & 29.1 & & Ref & \\
\hline 1998 & 47.9 & & 1.2 & $*$ & 35.3 & & 1.0 & & 28.7 & & 0.9 & \\
\hline 1999 & 51.3 & & 1.2 & $*$ & 38.5 & & 1.0 & & 29.6 & & 0.9 & \\
\hline 2000 & 56.6 & & 1.4 & $* * *$ & 44.1 & & 1.2 & $*$ & 36.2 & & 1.2 & \\
\hline 2001 & 58.7 & & 1.5 & $* * *$ & 44.9 & & 1.3 & $* * *$ & 38.3 & & 1.3 & * \\
\hline Tobacco-control $\times$ year interaction & & $* * *$ & & & & $* * *$ & & & & $* * *$ & & \\
\hline Tobacco-control states, 1997 & & & Ref & & & & Ref & & & & Ref & \\
\hline Tobacco-control states, 1998 & & & 1.0 & & & & 1.0 & & & & 1.3 & \\
\hline Tobacco-control states, 1999 & & & 0.8 & & & & 0.9 & & & & 1.2 & \\
\hline Tobacco-control states, 2000 & & & 0.7 & & & & 0.9 & & & & 0.7 & \\
\hline Tobacco-control states, 2001 & & & 0.9 & & & & 0.6 & ** & & & 0.9 & \\
\hline Electronic ad exposure & & *** & & & & $* * *$ & & & & *** & & \\
\hline Other & 43.8 & & Ref & & 32.9 & & Ref & & 26.7 & & Ref & \\
\hline Weekly+ & 58.6 & & 1.5 & $* * *$ & 45.9 & & 1.4 & $* * *$ & 38.4 & & 1.4 & *** \\
\hline Print ad exposure & & *** & & & & *** & & & & *** & & \\
\hline Other & 47.3 & & Ref & & 35.4 & & Ref & & 28.9 & & Ref & \\
\hline Weekly+ & 60.1 & & 1.5 & *** & 49.4 & & 1.5 & *** & 42.0 & & 1.5 & *** \\
\hline 5-year smoking intentions ${ }^{d}$ & & $* * *$ & & & & $* * *$ & & & & *** & & \\
\hline $\begin{array}{l}\text { Definitely would } \\
\text { not be smoking }\end{array}$ & 61.9 & & & & 49.5 & & & & 39.5 & & & \\
\hline Other & 39.6 & & & & 25.7 & & & & 21.3 & & & \\
\hline
\end{tabular}

${ }^{a}$ Model $N$ is 19,094 for 8th grade; 18,778 for 10th grade; and 9,071 for 12th grade.

${ }^{b}$ Percent respondents per grade reporting some + impact.

${ }^{c}$ Multivariate model odds ratio.

${ }^{d}$ Multivariate models do not include 5-year smoking intentions.

${ }^{*} p<.05 .{ }^{* *} p<.01 .{ }^{* * *} p<.001$. 


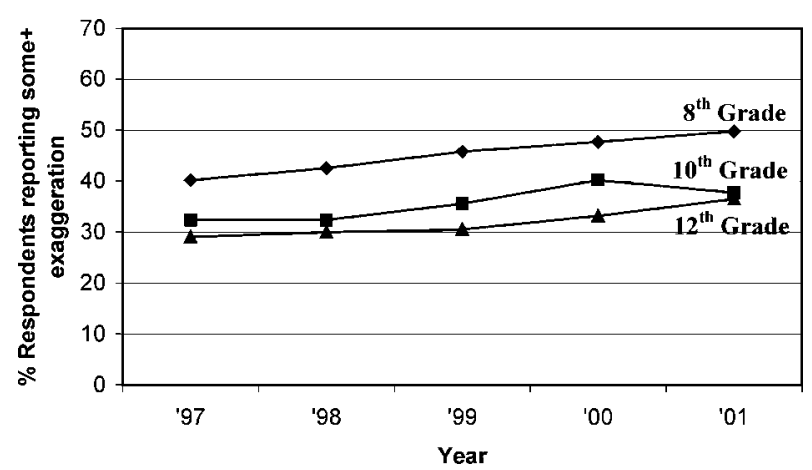

Fig. 6. Perceived exaggeration of anti-smoking advertising. Weighted sample $N$ s per year for perceived exaggeration are 8th grade $4,986-5,504 ; 10$ th grade $4,385-4,947 ; 12$ th grade $2,015-$ 2,444 .

(see Fig. 6). In 2001, almost $50 \%$ of 8 th graders reported that they felt ads exaggerated at least to some extent, compared to $37.7 \%$ of 10 th graders and $36.4 \%$ of 12 th graders. These numbers represent a mean increase of 7.5 percentage points from the 1997 data (for all 3 grades combined).

\section{Socio-Demographic Variation in Perceived Exaggeration}

The following variables were significantly related to differences in perceived exaggeration for all grades (see Table 6). Both African American and Hispanic students had higher odds than Whites of perceiving some or more exaggeration in anti-smoking advertising (ORs 1.3-1.7 and 1.4-1.7, respectively). Increased odds of believing that anti-smoking advertising exaggerated smoking risks were also observed for students with weekly or greater recalled exposure to both print (ORs 1.3) and electronic (ORs 1.4-1.6) anti-smoking advertising.

Interestingly, there was no evidence of a consistent pattern of tobacco-control-state residence or tobacco control state by year interaction for perceived exaggeration. Additional two-grade relationships were observed for parental education, current smoking, and year of study. Among 8th and 10th graders, high parental education lowered the odds of perceiving that the ads exaggerated smoking risks (ORs 0.8-0.9), as did any level of current smoking involvement (ORs $0.6-0.9$ for less than daily smoking, and $0.5-0.8$ for daily smoking). Eighth and tenth graders surveyed in 2000 and 2001 also reported higher odds of perceived exaggeration when compared to those surveyed in 1997 (ORs 1.2-1.3).

\section{DISCUSSION}

The aims of this paper are threefold: (a) to provide data with which to gauge the overall extent of exposure to anti-smoking media among youth at a national level, (b) to appraise general youth reactions to and appraisal of such advertising, and (c) to examine how such exposure reactions vary by sociodemographic characteristics.

Overall media consumption rates indicate that electronic media, especially television, are more likely than print media to reach youth for antismoking advertising, especially for younger grades. (The increased consumption of recreational computer use may have especially interesting implications for getting public health-related messages to American youth.) Electronic anti-smoking ads on television and radio had much higher rates of recall than did print, and these rates appear to be increasing. By 2001, almost two-thirds of all grades reported recalling such advertising weekly or more often. The overall rate of increase may, however, be reaching a plateau, potentially indicating saturation. It is important to note that recalled exposure to anti-smoking advertising significantly increased in tobacco-control states through 2001. Thus, even with the current implementation of nationwide anti-smoking advertising campaigns, state-based campaigns appear to make a significant difference in the odds of youth exposure to anti-smoking advertising. The indication of a possible saturation effect, however, may also be indicated by the significant interactions observed in the multivariate model for 2000 and 2001.

Socio-demographic differences in exposure were more common among 8th graders than 10th and 12th graders, possibly indicating that efforts to reach 10th and 12th graders should entail more targeted messages and/or programming times for White and female audiences. The finding that smokers had stronger recall of such messaging may simply be a factor of heavier TV watching; however, it may also indicate potential selective attention by smokers: the messages may create a level of cognitive dissonance with current behavior that increases memorability of the ads.

One question that might be raised from the observed findings deals with rates of electronic anti-smoking advertising recalled exposure in states 
Table 6. Socio-Demographic Differences in Some + Perceived Exaggeration of Anti-Smoking Advertising, 1997-2001 ${ }^{a}$

\begin{tabular}{|c|c|c|c|c|c|c|c|c|c|c|c|c|}
\hline \multirow[b]{3}{*}{ Independent variable } & \multicolumn{12}{|c|}{ Grade } \\
\hline & \multicolumn{4}{|c|}{8 th } & \multicolumn{4}{|c|}{ 10th } & \multicolumn{4}{|c|}{12 th } \\
\hline & $\%^{b}$ & $p(\%)$ & $\mathrm{OR}^{c}$ & $p(\mathrm{OR})$ & $\%$ & $p(\%)$ & OR & $p(\mathrm{OR})$ & $\%$ & $p(\%)$ & OR & $p(\mathrm{OR})$ \\
\hline Ethnicity & \multicolumn{3}{|c|}{ *** } & & \multicolumn{3}{|c|}{ *** } & \multicolumn{5}{|c|}{ *** } \\
\hline White & 41.8 & & Ref & & 31.1 & & Ref & & 28.2 & & Ref & \\
\hline African American & 49.7 & & 1.3 & $* * *$ & 45.9 & & 1.7 & $* * *$ & 39.8 & & 1.6 & $* * *$ \\
\hline Hispanic & 51.9 & & 1.4 & $* * *$ & 46.7 & & 1.6 & *** & 42.2 & & 1.7 & *** \\
\hline Gender & & & & & & & & & & $*$ & & \\
\hline Male & 44.2 & & Ref & & 35.9 & & Ref & & 32.9 & & Ref & \\
\hline Female & 45.8 & & 1.0 & & 35.2 & & 1.0 & & 30.3 & & 0.9 & \\
\hline Parental education & & $* *$ & & & & *** & & & & & & \\
\hline Low & 47.2 & & Ref & & 42.4 & & Ref & & 33.9 & & Ref & \\
\hline Medium & 46.9 & & 1.0 & & 35.7 & & 0.9 & $*$ & 31.8 & & 1.0 & \\
\hline High & 43.6 & & 0.9 & $*$ & 33.3 & & 0.8 & *** & 30.9 & & 1.0 & \\
\hline Grades & & & & & & $* * *$ & & & & $*$ & & \\
\hline B- and below & 44.4 & & Ref & & 37.9 & & Ref & & 33.7 & & Ref & \\
\hline $\mathrm{B}$ and higher & 45.3 & & 0.9 & & 33.8 & & 0.9 & $*$ & 30.7 & & 1.0 & \\
\hline College plans & & $* *$ & & & & & & & & * & & \\
\hline Other & 43.4 & & Ref & & 35.9 & & Ref & & 33.4 & & Ref & \\
\hline Definitely will graduate & 46.2 & & 1.1 & $*$ & 35.2 & & 1.0 & & 30.2 & & 0.9 & $*$ \\
\hline 30-day smoking & & $* * *$ & & & & $* * *$ & & & & * & & \\
\hline None & 47.3 & & Ref & & 37.3 & & Ref & & 32.6 & & Ref & \\
\hline$<$ Daily & 35.9 & & 0.6 & $* * *$ & 31.7 & & 0.9 & $*$ & 31.3 & & 1.0 & \\
\hline Daily+ & 30.6 & & 0.5 & $* * *$ & 29.8 & & 0.8 & *** & 28.2 & & 0.9 & \\
\hline Tobacco-control states & & *** & & & & $* * *$ & & & & *** & & \\
\hline Non-TC states & 43.7 & & Ref & & 33.7 & & Ref & & 29.9 & & Ref & \\
\hline TC states & 51.0 & & 1.2 & & 41.9 & & 1.5 & $* *$ & 39.8 & & 1.1 & \\
\hline Year & & *** & & & & *** & & & & $* *$ & & \\
\hline 1997 & 40.1 & & Ref & & 32.4 & & Ref & & 29.0 & & Ref & \\
\hline 1998 & 42.5 & & 1.1 & & 32.4 & & 1.0 & & 29.9 & & 1.0 & \\
\hline 1999 & 45.8 & & 1.1 & & 35.6 & & 1.1 & & 30.5 & & 1.0 & \\
\hline 2000 & 47.7 & & 1.2 & $* *$ & 40.2 & & 1.3 & $* *$ & 33.2 & & 1.1 & \\
\hline 2001 & 49.7 & & 1.2 & $*$ & 37.7 & & 1.3 & $* *$ & 36.4 & & 1.1 & \\
\hline \multicolumn{13}{|l|}{ Tobacco-control $\times$ year interaction } \\
\hline Tobacco-control states, 1997 & & & Ref & & & & Ref & & & & Ref & \\
\hline Tobacco-control states, 1998 & & & 0.9 & & & & 0.8 & & & & 1.2 & \\
\hline Tobacco-control states, 1999 & & & 1.1 & & & & 0.9 & & & & 1.4 & \\
\hline Tobacco-control states, 2000 & & & 0.8 & & & & 0.8 & & & & 1.2 & \\
\hline Tobacco-control states, 2001 & & & 1.0 & & & & 0.6 & $* *$ & & & 1.3 & \\
\hline Electronic ad exposure & & *** & & & & *** & & & & *** & & \\
\hline Other & 39.8 & & Ref & & 30.5 & & Ref & & 27.2 & & Ref & \\
\hline Weekly+ & 49.8 & & 1.3 & *** & 40.5 & & 1.3 & $* * *$ & 36.9 & & 1.3 & *** \\
\hline Print ad exposure & & *** & & & & $* * *$ & & & & *** & & \\
\hline Other & 41.1 & & Ref & & 31.5 & & Ref & & 28.6 & & Ref & \\
\hline Weekly+ & 53.0 & & 1.4 & $* * *$ & 45.5 & & 1.6 & *** & 40.8 & & 1.4 & *** \\
\hline 5 -year smoking intentions ${ }^{d}$ & & *** & & & & $* * *$ & & & & & & \\
\hline $\begin{array}{l}\text { Definitely would } \\
\text { not be smoking }\end{array}$ & 47.9 & & & & 36.9 & & & & 31.4 & & & \\
\hline Other & 41.7 & & & & 33.7 & & & & 31.9 & & & \\
\hline
\end{tabular}

${ }^{a}$ Model $N$ is 18,993 for 8 th grade; 18,710 for 10th grade; and 9,047 for 12th grade.

${ }^{b}$ Percent respondents per grade reporting some + exaggeration.

${ }^{c}$ Multivariate model odds ratio.

${ }^{d}$ Multivariate models do not include 5-year smoking intentions.

${ }^{*} p<.05 .{ }^{* *} p<.01 .{ }^{* * *} p<.001$. 
without campaigns and prior to the beginning of the national campaigns. During the time period 19971998 , approximately $35 \%$ of youth in such areas recalled seeing or hearing anti-smoking advertising weekly or more often (see Fig. 3). This background rate of exposure may well be attributable to PSAs from national voluntary agencies (including their state and local affiliates), low-level state-sponsored efforts, and commercial advertising for nicotine replacement products (that began around 1995).

Print counter-advertising was more likely to be recalled (thus indicating possibly higher true exposure levels) among minority youth and among young smokers. The number of billboards in urban settings with high minority populations has been found to be higher than similar settings with predominantly White populations (Lee \& Callcott, 1994; Mayberry $\&$ Price, 1993). Because the print advertising measure in this paper includes billboard anti-smoking ads, the higher ratio of billboards in urban minority neighborhoods may be playing a contributing factor in the observed increased recall. Because the data show that sources of media consumption broaden as students age, it may be important to consider a variety of media types for ad campaigns aimed at older students.

Increasing rates of recalled exposure were accompanied by increases in both the number of youth reporting that anti-smoking advertising made them less likely to smoke, as well as in the percentage of those who felt that such ads exaggerated smoking risks and consequences. The strength of these relationships was stronger for younger students. The relationship for judged impact was also stronger for females and (not surprisingly) nonsmokers. It may be important to emphasize that although any smoking activity seems to decrease the perceived impact of anti-smoking advertising, students with lessestablished smoking behaviors are more likely to report possibly being affected by an anti-smoking media message than daily smokers $(26 \%$ vs. $13 \%$ for 8 th graders; $23 \%$ vs. $11 \%$ for 10 th graders, and $24 \%$ vs. $12 \%$ for 12 th graders; see Table 5 ). As noted previously, reported levels of judged impact of antismoking advertising cannot be directly equated with behavior change. However, these data do indicate that level of exposure to anti-smoking advertising seems to be related to contemplating change in individual smoking behaviors. The results on the similar trends for perceived exaggeration of anti-smoking advertising are less clear. As noted in "Introduction," research is inconclusive on the possible ramifications of the level to which ads are perceived to exaggerate behavior risks.

The importance of understanding the extent of exposure to anti-smoking media among American youth, as well as their appraisal of such advertising, is based on findings indicating that these media efforts may be successful components of efforts to lower youth smoking rates. The data presented in this paper may serve as useful indicators for those considering optimum use of available funding for anti-smoking media campaigns. However, a host of questions remain that need to be addressed in further research. First, this study was unable to examine exposure to anti-tobacco messages in nontraditional mass media, such as community-based events, sporting programs, or media portrayals. Media planners who have taken advantage of such intervention approaches have had little data by which to gauge the possible effectiveness of such efforts. Second, while these data show that students in states with antismoking media campaigns clearly show higher levels of recalled exposure to the advertising, as well as higher levels of judged impact (and exaggeration), there may be threshold levels past which additional advertising shows little increased response.

Further, all advertising is certainly not equal. Although the analyses reported in this paper group state anti-tobacco campaigns together for an overall examination of student responses, significant qualitative and quantitative variation exists among state campaigns, including audiences targeted (youth, parents, or the general public) and the types of message themes used. Examinations of construct validity for both recalled exposure to electronic anti-smoking advertisements and judged impact indicate that antismoking advertising campaigns appear not to affect targeted audiences equally across measures that are associated with youth smoking beliefs and/or behaviors. Increases in overall levels of recall that matched the date on which Philip Morris began airing its campaigns did not show a concurrent influence on levels of judged impact. While research into antismoking advertising has begun to uncover differences in ad effects (e.g., Biener 2002; Biener et al., 2000; Pechmann \& Reibling, 2000; Pechmann et al., 2003; Terry-McElrath et al., in press; Wakefield et al., 2003a), clearly, additional work is needed to determine which approaches best reach youth. This research should examine which advertising messages and themes are being communicated (and at what levels) and if youth respond differently to such content. It may be that increases in both judged impact 
and perceived exaggeration of smoking risks are related to competing advertising themes, messages, and formats.

\section{ACKNOWLEDGMENTS}

This paper was supported by grants from The Robert Wood Johnson Foundation (032769), The National Institute on Drug Abuse (DA01411), and the National Cancer Institute (CA86273-01). The views expressed in this paper are those of the authors and do not necessarily reflect the views of the sponsors. The authors would like to thank Tanya Hart for editorial assistance, as well as the many schools and students that participated in the surveys.

\section{REFERENCES}

Bachman, J. G., Johnston, L. D., \& O'Malley, P. M. (2001). The monitoring the future project after 27 years: Design and procedures. (Monitoring the Future Occasional Paper No. 54). Ann Arbor, MI: Institute for Social Research, University of Michigan.

Bauer, U., Johnson, T., Pallentino, J., Hopkins, R., McDaniel, W., \& Brooks, R. G. (1999). Tobacco use among middle and high school students-Florida, 1998 and 1999. Morbidity and Mortality Weekly Report, 48, 248-253.

Bauer, U., Johnson, T. M., Hopkins, R. S., \& Brooks, R. G. (2000). Changes in youth cigarette use and intentions following implementation of a tobacco control program. Journal of the American Medical Association, 284, 723-728.

Bauman, K. E., LaPrelle, J., Brown, J. D., Koch, G. G., \& Padgett, C. A. (1991). The influence of three mass media campaigns on variables related to adolescent cigarette smoking: Results of a field experiment. American Journal of Public Health, 81(5), $597-604$.

Biener, L. (2002). Anti-tobacco advertisements by Massachusetts and Philip Morris: What teenagers think. Tobacco Control, 11(Suppl II), ii43-ii46.

Biener, L., \& Taylor, T. M. (2002). The continuing importance of emotion in tobacco control media campaigns: A response to Hastings and MacFadyen. Tobacco Control, 11, 75-77.

Biener, L., McCallum-Keeler, G., \& Nyman, A. L. (2000). Adults' response to Massachusetts anti-tobacco television advertisements: Impact of viewer and advertisement characteristics. Tobacco Control, 9, 401-407.

Biglan, A., Ary, D. V., Smolkowski, K., Duncan, T., \& Black, C. (2000). A randomized controlled trial of a community intervention to prevent adolescent tobacco use. Tobacco Control, 9, 24-32.

Briton, N. J., Clark, T. W., Krakow, M., Soldz, S., Baker, A. K., \& Posner, J. (1997). Adolescent tobacco use in Massachusetts: Trends among public school students, 1984-1996. Boston, MA: Massachusetts Department of Public Health.

Farrelly, M. C., Healton, C. G., Davis, K. C., Messeri, P., Hersey, J. C., \& Haviland, M. L. (2002). Getting to the truth: evaluating national tobacco countermarketing campaigns. American Journal of Public Health, 92(6), 901-907.

Flay, B. R., Brannon, B. R., Johnson, C. A., Hansen, W. B., Ulene, A. L., Whitneysaltiel, D. A., Gleason, L. R., Sussman, S., Gavin, M. D., Glowacz, K. M., Sobol, D. F., \& Spiegel,
D. C. (1988). The television, school and family smoking prevention and cessation project. 1 . Theoretical basis and program development. Preventive Medicine, 17, 585-607.

Flay, B. R., Miller, T. Q., Hedeker, D., Siddiqui, O., Britton, C. F., Brannon, B. R., Johnson, C. A., Hansen, W. B., Sussman, S., \& Dent, C. (1995). The television, school, and family smoking prevention and cessation project. VII. Student outcomes and mediating variables. Preventive Medicine, 24, 2940.

Flynn, B. S., Worden, J. K., Secker-Walker, R. H., Badger, G. J., Geller, B. M., \& Costanza, M. C. (1992). Prevention of cigarette smoking through mass media intervention and school programs. American Journal of Public Health, 82(6), 827-834.

Flynn, B. S., Worden, J. K., Secker-Walker, R. H., Pirie, P. L., Badger, G. J., Carpenter, J. H., \& Geller, B. M. (1994). Mass media and school interventions for cigarette smoking prevention: Effects 2 years after completion. American Journal of Public Health, 84(7), 1148-1150.

Hafstad, A., Aaro, L. E., Engeland, A., Andersen, A., Langmark, F., \& Stray-Pedersen, B. (1997). Provocative appeals in antismoking mass media campaigns targeting adolescents-The accumulated effect of multiple exposures. Health Education Research, 12(2), 227-236.

Harris, J. E., Connolly, G. N., Brooks, D., \& Davis, B. (1996). Cigarette smoking before and after an excise tax increase and an anti-smoking campaign-Massachusetts, 1990-1996. Morbidity and Mortality Weekly Report, 45, 996-1070.

Hill, D., Chapman, S., \& Donovan, R. (1998). The return of scare tactics. Tobacco Control, 7, 5-8.

Hu, T., Sung, H. Y., \& Keeler, T. E. (1995). Reducing cigarette consumption in California: Tobacco taxes vs. an anti-smoking media campaign. American Journal of Public Health, 85(9), 1218-1222.

Johnson, C. A., Pentz, M. A., \& Weber, M. D. (1990). Relative effectiveness of comprehensive community programming for drug abuse prevention with high-risk and low-risk adolescents. Journal of Consulting \& Clinical Psychology, 58, 447456.

Johnston, L. D., O'Malley, P. M., \& Bachman, J. G. (2002). Monitoring the future national survey results on drug use, 1975-2001. Volume 1: Secondary school students (NIH Publication No. 02-5106). Bethesda, MD: National Institute on Drug Abuse.

Lee, W. N., \& Callcott, M. F. (1994). Billboard advertising: A comparison of vice products across ethnic groups. Journal of Business Research, 30, 85-94.

Lewit, E., Coate, D., \& Grossman, M. (1981). The effects of government regulation on teenage smoking. Journal of Law and Economics, 24, 545-569.

Logan, R. A., \& Longo, D. R. (1999). Rethinking anti-smoking media campaigns: Two generations of research and issues for the next. Journal of Health Care Finance, 25(4), 77-90.

Mayberry, R. M., \& Price, P. A. (1993). Targeting blacks in cigarette billboard advertising: Results from down South. Health Values: The Journal of Health Behavior, Education \& Promotion, 17(1), 28-35.

McKenna, J., Gutierrez, K., \& McCall, K. (2000). Strategies for an effective youth counter-marketing program: Recommendations from commercial marketing experts. Journal of Public Health Management Practice, 6(3), 7-13.

Mudde, A. N., \& De Vries, H. (1999). The reach and effectiveness of a national mass media-led smoking cessation campaign in the Netherlands. American Journal of Public Health, 89(3), 346-350.

Murray, D. M., Perry, C. L., Griffin, G., Harty, K. C., Jacobs, D. R., Schmid, L., Daly, K., \& Pallonen, U. (1992). Results from a statewide approach to adolescent tobacco use prevention. Preventive Medicine, 21, 449-472. 
Murray, D. M., Prokhorov, A. V., \& Harty, K. C. (1994). Effects of a statewide antismoking campaign on mass media messages and smoking beliefs. Preventive Medicine, 23, 54-60.

Oregon Department of Human Services. (2003). Make Oregon healthier: Saving lives and saving dollars. Tobacco prevention and education in Oregon. Program report 2001-2003. Salem, OR: Department of Human Services.

Pechmann, C. (1997). Does antismoking advertising combat underage smoking? A review of past practices and research. In M. E. Goldberg, M. Fishbein, S. Middlestadt (Eds.), Social marketing: Theoretical and practical perspectives (pp. 189-216). Hillsdale, NJ: Lawrence Erlbaum Associates.

Pechmann, C., \& Reibling, E.T. (2000). Anti-smoking advertising campaigns targeting youth: Case studies from USA and Canada. Tobacco Control, 9(Suppl II), ii0-ii13.

Pechmann, C., Zhao, G., Goldberg, M. E., \& Reibling, E. T. (2003). What to convey in antismoking ads for adolescents? The use of protection motivation theory to identify effective message themes. Journal of Marketing, 67(2), 1-18.

Pentz, M. A., Dwyer, J. H., \& MacKinnon, D. P. (1989a). A multicommunity trial for primary prevention of adolescent drug abuse. Journal of the American Medical Association, 261, 3259-3266.

Pentz, M. A., MacKinnon, D. P., Dwyer, J. H., Wang, E. Y. I., Hansen, W. B., Flay, B. R., \& Johnson, C. A. (1989b). Longitudinal effects of the Midwestern Prevention Project on regular and experimental smoking in adolescents. Preventive Medicine, 18, 304-321.

Perry, C. L., Kelder, S. H., Murray, D. M., \& Klepp, K. I. (1992). Communitywide smoking prevention: Long-term outcomes of the Minnesota Heart Health Program and the Class of 1989 Study. American Journal of Public Health, 82(9), 1210 1216.

Pierce, J. P., Choi, W. S., Gilpin, E. A., Farkas, A. J., \& Merritt, R. K. (1996). Validation of susceptibility as a predictor of which adolescents take up smoking in the United States. Health Psychology, 15, 355-361.

Pierce, J. P., Emery, S., \& Gilpin, E. (2002). The California tobacco control program: A long-term health communication project. In R. C. Hornik (Ed.), Public health communication: Evidence for behavior change (pp. 97-114). Mahwah, NJ: Lawrence Erlbaum Associates.

Popham, W. J., Potter, L. D., Hetrick, M. A., Muthén, L. K., Duerr, J. M., \& Johnson, M. D. (1994). Effectiveness of the California 1990-1991 tobacco education media campaign. American Journal of Preventive Medicine, 10(6), 319326.

Raghunathan, T. E., Solenberger, P. W., \& Van Hoewyk, J. (2002). IVEware: Imputation and variance estimation software. Ann Arbor, MI: Survey Methodology Program, Survey Research Center, Institute for Social Research, University of Michigan.
Schneider, L., Klein, B., \& Murphy, K. (1981). Government regulation of cigarette health information. Journal of Law and Economics, 24, 575-612.

Siegel, M., \& Biener, L. (2000). The impact of an antismoking media campaign on progression to established smoking: Results of a longitudinal youth study. American Journal of Public Health, 90(3), 380-386.

Siegel, M., \& Biener, L. (2002). The impact of antismoking media campaigns on progression to established smoking: Results of a longitudinal youth study in Massachusetts. In R. C. Hornik (Ed.), Public health communication: Evidence for behavior change (pp. 115-130). Mahwah, NJ: Lawrence Erlbaum Associates.

Sly, D., Heald, G. R., \& Ray S. (2001a). The Florida "Truth" anti-tobacco media evaluation: Design, first year results and implications for planning future media evaluations. Tobacco Control, 10, 9-15.

Sly, D. F., Hopkins, R. S., Trapido, E., \& Ray, S. (2001b). Influence of a counteradvertising media campaign on initiation of smoking: The Florida "truth" campaign. American Journal of Public Health, 91, 233-238.

Sly, D. F., Trapido, E., \& Ray, S. (2002). Evidence of the dose effects of an antitobacco counteradvertising campaign. Preventive Medicine, 35, 511-518.

Smith, K. H., \& Stutts, M. A. (1999). Factors that influence adolescents to smoke. The Journal of Consumer Affairs, 33(2), 321-357.

Terry-McElrath, Y., Wakefield, M., Ruel, E., Balch, G. I., Emery, S., Szczypka, G., Clegg-Smith, K., \& Flay, B. (in press). The effect of anti-smoking advertisement characteristics on youth appraisal and engagement. Journal of Health Communication.

Wakefield, M., Durrant, R., Terry-McElrath, Y., Ruel, E., Balch, G., Anderson, S., Hastings, G., Szczypka, G., \& Flay, B. (2003a). Appraisal of anti-smoking advertising by youth at risk for regular smoking: A comparative study in the United States, Australia, and Britain. Tobacco Control, 12(Suppl 11), ii82-ii86.

Wakefield, M., Flay, B., Nichter, M., \& Giovino, G. (2003b). Effects of anti-smoking advertising on youth smoking: A review. Journal of Health Communication, 8, 229-247.

Wakefield, M., Flay, B., Nichter, M., \& Giovino, G. (2003c). Role of the media in influencing trajectories of youth smoking. Addiction, 98(Suppl 1), 79-103.

Warner, K. E. (1977). The effects of the anti-smoking campaign on cigarette consumption. American Journal of Public Health, 67(7), 645-650.

Warner, K. E. (1979). Clearing the airwaves: The cigarette ad ban revisited. Policy Analysis, 5, 435-450.

Winkelby, M. A., Fortmann, S. P., \& Rockhill, B. (1993). Cigarette smoking trends in adolescents and young adults: The Stanford Five City Project. Preventive Medicine, 22, 325-334. 